n. 1 (maio.2020)

\title{
A UTILIZAÇÃO DO CONTRATO DE CONVIVÊNCIA DA UNIÃO ESTÁVEL NAS RELAÇÕES DE FAMÍLIAS POLIAFETIVAS
}

\author{
Fernanda Victória Meneses da Silva ${ }^{1}$
}

Resumo: O presente trabalho analisa o debate sobre a utilização das escrituras públicas de união estável para registro das uniões poliafetivas no ordenamento jurídico brasileiro. O princípio da monogamia é considerado um dos pilares do instituto do casamento, todavia, existe uma grande quantidade de pessoas que não aderem a esse tipo de relacionamento, e estes indivíduos tendem a ficar à margem do direito, tendo em vista que não há instituto jurídico que defendam a forma com que escolheram viver. A utilização da escritura pública de união estável chegou a ser cogitada e utilizada em algumas situações, porém, a posição do CNJ é de que não mais sejam feitas tais escrituras, com o argumento de que há uma violação do direito na realização destes atos. Este artigo realiza um desdobramento de todos os institutos utilizados para a validação jurídica de uma família, perpassando pelo casamento, união estável, examinando a monogamia como instituto moral e debatendo as posições favoráveis e contrárias ao registro das uniões poliafetivas.

Palavras-chave: Poliafetividade. Monogamia. Registro. Escritura.

\section{INTRODUÇÃO}

Dentro do direito, a família é vista como "base da sociedade", como

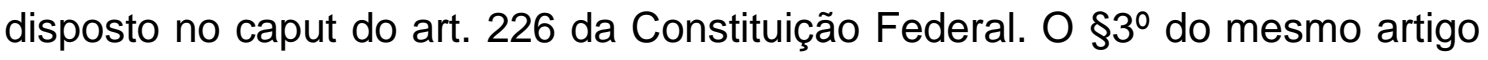
afirma que "é reconhecida a união estável entre o homem e a mulher como entidade familiar, devendo a lei facilitar sua conversão em casamento". $\mathrm{Na}$ mesma linha, pode ser citado o $\$ 4^{\circ}$ do mesmo Diploma Legal, o qual aduz que "entende-se, também, como entidade familiar, a comunidade formada por qualquer dos pais e seus descendentes".

Estes são somente alguns dos conceitos que são utilizados no âmbito jurídico para chegarmos a uma definição do que seria, efetivamente, família. $O$ instituto é amplo e não está imune a mutações, sendo notável a sua

\footnotetext{
${ }^{1}$ Graduanda do curso de Direito da Universidade Federal da Bahia - UFBA. Integrante do grupo de pesquisa em Direito e Sexualidade da Faculdade de Direito da UFBA.
} 
n. 1 (maio.2020)

transformação ao longo dos anos: pode-se citar, por exemplo, épocas nas quais o casamento era a única forma aceita para validação da relação frente ao direito.

As modificações que ocorreram neste campo não foram rápidas nem tampouco aceitas com unanimidade: ainda existem aqueles que não veem sentido na realização de uma união estável e que até mesmo permanecem contrários ao casamento homoafetivo, citado por ser uma das alterações legislativas mais recentes.

As uniões poliafetivas tendem a seguir por essa mesma linha, sendo, ainda, fonte de inúmeros debates com fortes posições favoráveis e contrárias, não tendo encontrado um "meio-termo" em que possa existir. Boa parte da sociedade atual repudia qualquer forma de relacionamento que venha contrária à monogamia, e, para que a poliafetividade venha a ter seu espaço, é necessário que ocorra o seu reconhecimento jurídico para que integrantes de tais relações possam vir a ter seus direitos garantidos.

Essa realidade não é nova, contudo, é fortemente ignorada, sendo necessária a possibilidade de reconhecimento jurídico do tema no país e que a sua permissão seja, de fato, concedida, não havendo razões para a exclusão jurídica dessas uniões no país.

\section{PRINCÍPIO DA MONOGAMIA}

A discussão que ocorre atualmente dentro das questões principiológicas do Direito de Família é se a monogamia pode ou não ser considerada um princípio. De acordo com Frederico Fernandes dos Santos²:

(...) os princípios, além de serem a origem, a base de sustentação da norma, também são ideias mais genéricas - de onde se pode extrair concepções e

2 SANTOS, Frederico Fernandes dos. 0 que são princípios? Suas fases, distinções e juridicidade. Disponível em: <https://jus.com.br/artigos/45194/o-que-sao-principios-suas-fasesdistincoes-e-juridicidade>. Acesso em 9 jan.2019. 
intenções para a criação de outras normas, ou encontrar a sua sustentação em caso de lacunas na sua aplicação. É o que bem se observa no art. $4^{\circ}$ da LINDB - Lei de Introdução as Normas de Direito Brasileiro, no art. 8o parágrafo único da CLT Consolidação das Leis do Trabalho, bem como no art. 126 do CPC - Código de Processo Civil, todos afirmam que, em caso de omissão de regra, o juiz deve decidir a lide baseado em analogia, costumes e princípios gerais de direito.

Existem aqueles que defendem o fato de a monogamia ser uma base que estrutura o Direito de Família, mas, seguindo à risca o conceito de princípio defendido por diversos autores, não acreditam que ela é um grande norte moral para o ordenamento jurídico. Seguindo essa linha, Rodrigo da Cunha Pereira ${ }^{3}$ sustenta que:

O princípio da monogamia, embora funcione também como um ponto-chave das conexões morais das relações amorosas e conjugais, não é simplesmente uma norma moral das relações amorosas e conjugais, não é simplesmente uma norma moral ou moralizante. Sua existência nos ordenamentos jurídicos que o adotam tem a função de um princípio jurídico ordenador. Ele é um princípio básico e organizador das relações jurídicas da família no mundo ocidental.

O mesmo autor ${ }^{4}$ defende que a monogamia funciona como um ponto chave das conexões morais de uma determinada sociedade, todavia, não pode ter sua aplicação de forma que inviabilize direitos. A monogamia como princípio deve ser utilizada e ponderada com outros valores e princípios - especialmente o da dignidade humana. O rompimento do princípio da monogamia, para o autor, significaria estabelecer outro código moral em relação ao parceiro ou parceira.

\footnotetext{
${ }^{3}$ PEREIRA, Rodrigo da Cunha. Princípios fundamentais e norteadores para a organização jurídica da família. 2004. 157 f. Tese (Doutorado em Direito) - Curitiba: Faculdade de Direito, Universidade Federal do Paraná - UFPR, 2004 APUD ANDRADE, Marcelo Caetano Bittencourt Pizzani Ribeiro de. Respirar o amor aspirando liberdade: o poliamor no ordenamento jurídico brasileiro. Salvador: Faculdade de Direito da UFBA, Universidade Federal da Bahia UFBA, 2018.
}

4 IBDFAM. Monogamia, desejo e famílias paralelas. Disponível em: < http://www.ibdfam.org.br/noticias/4989/Monogamia,+desejo+e+fam\%C3\%ADlias+paralelas>. Acesso em 9 jan. 2019. 
n. 1 (maio.2020)

Marcos Alves da Silva ${ }^{5}$ afirma que a monogamia, sendo regra ou princípio, sempre constituiu uma forma de controle da sexualidade, mormente a da mulher. Ela foi erigida à condição de princípio jurídico par e passo à construção da regra da presunção da paternidade do marido aos filhos nascidos de sua mulher. $O$ controle da sexualidade feminina constituiu e, de certa forma, ainda constitui instrumento de controle da prole do marido.

Esse princípio iria pressupor uma família que fosse merecedora da tutela do Estado e outra que fique fora deste âmbito de proteção. A superação do princípio da monogamia seria justificada pela defesa da pluralidade de entidades familiares e da superação do casamento como o modelo superior reconhecido pelo Estado.

O mesmo autor citado acima ${ }^{6}$ também diz que o ordenamento jurídico brasileiro caminha para a superação do princípio da monogamia como base do direito de família. O tema, antes da Constituição de 1988, só era tratado quando se falava sobre o concubinato adulterino. Os novos arranjos familiares da família do século XXI refletem a transformação da sociedade brasileira. De acordo com Censo do Instituto Brasileiro de Geografia e Estatística (IBGE) 7 feito em 2010, havia, no Brasil, 89,6 milhões de solteiros, 5 milhões de divorciados e 2,8 milhões de separados judicialmente, enquanto o número de casados chegava a 56 milhões.

Vale acrescentar o posicionamento de Carlos Eduardo Pianovski $\mathrm{Ruzyk}^{8}$, que reconhece a monogamia como característica de longa duração da

5 IBDFAM. Uniões simultâneas, monogamia e dever a fidelidade. Disponível em: <http://www.ibdfam.org.br/noticias/5153/Uni\%C3\%B5es+simult\%C3\%A2neas\%2C+monogamia +e+dever+a+fidelidade $>$. Acesso em 18 dez. 2018.

6 SILVA, Marcos Alves da. Da superação da monogamia como princípio estruturante do estatuto jurídico da família. 2012. $295 \mathrm{f}$. Tese (Doutorado em Direito). Rio de Janeiro: Faculdade de Direito, Universidade do Estado do Rio de Janeiro, 2012.

7 IBGE - INSTITUTO BRASILEIRO DE GEOGRAFIA E ESTATÍSTICA. Nupcialidade e fecundidade. Disponível em: < https://cnae.ibge.gov.br/en/component/content/article/957a12/7a12-vamos-conhecer-o-brasil/nosso-povo/1472-nupcialidade-e-

fecundidade.html? ltemid=6160 $>$. Acesso em 13 mar. 2019.

8 RUZYK, Carlos Eduardo Pianovski. Famílias simultâneas: da unidade codificada à pluralidade constitucional. Rio de Janeiro: Renovar, 2005 APUD SILVA, Marcos Alves da. Da superação da monogamia como princípio estruturante do estatuto jurídico da família. 2012. 295 f. Tese (Doutorado em Direito). Rio de Janeiro: Faculdade de Direito, Universidade do Estado do Rio de Janeiro, 2012. 
família ocidental, mas que ela não pode ser tomada como a absolutização de um dado histórico. Ele conclui que:

(...) tomar o princípio jurídico da monogamia como um 'dever-ser' imposto pelo Estado a todas as relações familiares é algo que entra em conflito com a liberdade que deve prevalecer naquela que é uma das searas da vida na qual os sujeitos travam algumas das mais relevantes relações no tocante à formação de sua subjetividade e desenvolvimento de sua personalidade.

Maria Berenice Dias ${ }^{9}$ segue pela mesma linha de pensamento dos autores acima, afirmando que a monogamia não se trata de um princípio do direito estatal de família, mas sim uma regra que busca proibir as múltiplas relações matrimonializada chanceladas pelo Estado.

A Constituição Federal, de acordo com a autora, tanto tolera a traição que não permite que os filhos se sujeitem a qualquer tipo de discriminação, mesmo quando se tratar de prole constituída de uma relação adulterina ou incestuosa. O princípio da monogamia serviria muito mais as questões patrimoniais, sucessórias e econômicas.

Todavia, as ideias acima citadas não se encontram em maioria. Autores tradicionais, como, por exemplo, Orlando Gomes ${ }^{10}$, sustentam que 0 vínculo deve, sim, ser monogâmico:

O vínculo matrimonial há de resultar do consentimento livre dos nubentes. Pressupõe, por conseguinte, capacidade para manifestá-lo. O consentimento dos contraentes não pode ser substituído, nem se admite seja a vontade autolimitada pela condição ou por termo. Tem de ser monogâmico. Não se permite a existência simultânea de dois ou mais vínculos matrimoniais contraídos pela mesma pessoa. A bigamia é punida. Quem é casado está proibido de contrair segundas núpcias, defesas enquanto permanece o vínculo. Nessa proibição consiste, tecnicamente, a monogamia.

${ }^{9}$ DIAS, Maria Berenice. Manual de Direito de Família. São Paulo: Editora Revista dos Tribunais, 2016.

10 GOMES, Orlando. Direito de Família. Rio de Janeiro: Forense, 2000. 
n. 1 (maio.2020)

Rolf Madaleno ${ }^{11}$ também é um dos autores que defendem a monogamia como um princípio. Ele sustenta que o princípio da monogamia continua sendo ordenador de uma conduta humana ao menos preferencial de organização das relações jurídicas da família do mundo ocidental.

Não poderia deixar de ser citada Regina Beatriz Tavares da Silva ${ }^{12}$, advogada especializada em Direito de Família que por diversas vezes já se manifestou contrária à quebra do princípio da monogamia. Em um de seus artigos sobre o tema, ela alega que as sociedades monogâmicas são mais aptas a gerar melhor organização social e melhores benefícios econômicos.

Dessa forma, percebe-se que, mesmo com todas as controvérsias e debates a respeito do tema, a monogamia ainda é, mesmo que de forma inconsciente - a monogamia é seguida pela maioria dos indivíduos que adentram relações com outros, sejam elas homo ou heterossexuais, tendo em vista que a ideia da relação monogâmica ser a correta está enraizada no imaginário das pessoas -, utilizada como princípio no Direito de Família.

\section{O CASAMENTO}

De acordo com Flávio Tartuce ${ }^{13}$, o casamento pode ser definido como a união entre duas pessoas, devidamente reconhecida e regulamentada pelo Estado, com o animus de constituir família e baseado em um vínculo de afeto. $O$ conceito apresentado por esse autor engloba a decisão dada pelo STF em 2011 sobre união homoafetiva, tendo em vista que, desde o mencionado ano, o casamento entre pessoas do mesmo sexo passou a ser reconhecido.

\footnotetext{
11 Carta Forense. Escritura de união poliafetiva: impossibilidade. Disponível em: $<$ http://www.cartaforense.com.br/conteudo/artigos/escritura-de-uniao-poliafetivaimpossibilidade/9754>. Acesso em 18 dez. 2018.

12 SILVA, Regina Beatriz Tavares da. As tentativas de destruição da Família Brasileira. Disponível em: <http://www.reginabeatriz.com.br/as-tentativas-de-destruicao-da-familiabrasileira>. Acesso em 18 dez. 2018.

13 TARTUCE, Flávio. Direito civil, v. 5: Direito de família. 12 ed. rev., atual e ampl. Rio de Janeiro: Forense, 2017.
} 
É importante ressaltar essa decisão, haja vista que, em uma relação poliafetiva, onde todos os seus componentes relacionam-se entre si, necessariamente haverá a formação de uma relação homoafetiva, seja ela entre dois homens ou duas mulheres que componham essa união. O CNJ decidiu no mesmo sentido ao publicar a resolução $n^{0} \mathbf{1 7 5 ^ { 1 4 }}$, de 14 de maio de 2013 , a qual traz o seguinte texto:

CONSIDERANDO a decisão do plenário do Conselho Nacional de Justiça, tomada no julgamento do Ato Normativo no 000262665.2013.2.00.0000, na 169 a Sessão Ordinária, realizada em 14 de maio de 2013; CONSIDERANDO que o Supremo Tribunal Federal, nos acórdãos prolatados em julgamento da ADPF 132/RJ e da ADI 4277/DF, reconheceu a inconstitucionalidade de distinção de tratamento legal às uniões estáveis constituídas por pessoas de mesmo sexo; CONSIDERANDO que as referidas decisões foram proferidas com eficácia vinculante à administração pública e aos demais órgãos do Poder Judiciário; CONSIDERANDO que o Superior Tribunal de Justiça, em julgamento do RESP 1.183.378/RS, decidiu inexistir óbices legais à celebração de casamento entre pessoas de mesmo sexo; CONSIDERANDO a competência do Conselho Nacional de Justiça, prevista no art. 103B, da Constituição Federal de 1988; RESOLVE: Art. 1ํ É vedada às autoridades competentes a recusa de habilitação, celebração de casamento civil ou de conversão de união estável em casamento entre pessoas de mesmo sexo. Art. 2o A recusa prevista no artigo $1 \%$ implicará a imediata comunicação ao respectivo juiz corregedor para as providências cabíveis. Art. 30 Esta resolução entra em vigor na data de sua publicação.

O casamento passou por diversas modificações na lei que o regulou durante a história, para que pudesse se adequar à sociedade. Em 1889, ano da Proclamação da República, a única forma de se constituir essa união seria pelo meio religioso. O casamento civil surgiu em 1891, tendo sido nele incorporado questões pertencentes ao meio religioso, como a sua indissolubilidade, que foi

${ }^{14}$ CONSELHO NACIONAL DE JUSTIÇA. Resolução no 175, de 14 de maio de 2013. Disponível em: < http://www.cnj.jus.br/busca-atos-adm?documento=2504>. Acesso em 23 mai 2019. 
consagrada na legislação. Ainda não havia sido criada a Lei do Divórcio - lei no 6.515/1977 -, e, como o casamento foi consagrado como indissolúvel, a forma da sua desconstituição era dada pelo desquite, todavia, permaneceu a ideia de família patriarcal com composição somente matrimonial. Com o advento da Constituição de 1988, foram convalidadas outras formas de criação de famílias e vínculos parentais, como o reconhecimento da família monoparental. A união estável também passou a ser outorgada a partir dessa codificação.

De acordo com Maria Berenice Dias:

O casamento gera o que se chama de estado matrimonial, no qual os nubentes ingressam por vontade própria, por meio da chancela estatal. Historicamente a família nasce quando da celebração do casamento, que assegura direitos e impõe deveres no campo pessoal e patrimonial. As pessoas têm a liberdade de casar, mas, uma vez que se decidam, a vontade delas se alheia e só a lei impera na regulamentação de suas relações.

O Código Civil brasileiro não traz uma definição do que seria o casamento. $\mathrm{O}$ assunto começa a ser abordado na Codificação a partir do artigo $1.511^{15}$, que define qual a sua finalidade. Outros Códigos ao redor do mundo também não possuem essa preocupação, como apontam Pablo Stolze Gagliano e Rodolfo Pamplona Filho ${ }^{16}$, que acreditam ser essa tarefa da doutrina especializada.

Com relação à natureza jurídica do casamento, é sustentado que esse instituto faz parte do Direito Privado, e são diversas as correntes com relação a esta definição. Uma parte da doutrina acredita ser um ato-condição, e também defendem as ideias de natureza contratual, acordo de vontades, e estatuto de normas.

Assim, concluímos que as legislações ao redor do mundo não trazem uma definição exata do que seria o instituto do casamento, não sendo ele

15 Art. 1.511. O casamento estabelece comunhão plena de vida, com base na igualdade de direitos e deveres dos cônjuges.

${ }^{16}$ GAGLIANO, Pablo Stolze; PAMPLONA FILHO, Rodolfo. Novo curso de direito civil - volume 6: Direito de família - As famílias em perspectiva constitucional. São Paulo: Saraiva, 2012. 
n. 1 (maio.2020)

imutável e estando em constante modificação para que possa se adequar as transformações que a sociedade vem sofrendo ao longo dos anos.

\section{A UNIÃO ESTÁVEL}

Não é correto concluir que o casamento é a única entidade familiar que pode ser juridicamente reconhecida, e, além disso, não se pode afirmar que todos os grupos de entidades familiares têm interesse em regularizar e formalizar judicialmente a situação em que se encontram. A união estável pode ser vista como uma alternativa ao instituto do casamento, que era extremamente valorizado no Código Civil de 1916. Essa realidade foi sendo alterada aos poucos, até chegar no modelo que conhecemos atualmente.

É possível agrupar a evolução histórica da união estável no ordenamento jurídico brasileiro em momentos visivelmente distintos, tendo início com a sua ampla rejeição, passando pela simples tolerância, aceitação natural como fato social, e, finalmente, seu reconhecimento e valorização constitucional como uma outra forma de família ${ }^{17}$.

O objetivo do Código Civil de 1916 era proteger as famílias formadas pelo vínculo sagrado do matrimônio, omitindo-se com relação aos laços que eram constituídos fora dessa relação. A união feita fora do casamento era denominada concubinato, termo considerado pejorativo, com o objetivo de marginalizar aqueles que escolhiam viver dessa maneira. De acordo com Rodrigo da Cunha Pereira ${ }^{18}$ :

Principalmente entre leigos, a palavra concubina não é simplesmente significado de uma forma de vida, a indicação de estar vivendo com outra pessoa. Quando não é motivo de deboche, é indicativa de uma relação "desonesta" ou "ilegítima".

17 GAGLIANO, Pablo Stolze. Novo curso de direito civil - volume 6: Direito de família - As famílias em perspectiva constitucional. São Paulo: Saraiva, 2012.

18 PEREIRA, Rodrigo da Cunha. Direito de família: uma abordagem psicanalítica. Rio de Janeiro: Editora Forense, 2012. 
Havia, ainda, a tentativa de distinguir a ideia do "concubinato puro" utilizado para identificar a situação do indivíduo que escolhia viver em concubinato sem possuir nenhum tipo de impedimento - e o "concubinato impuro" - o qual caracterizava o sujeito que possuía algum tipo de impedimento para a realização do ato, como, por exemplo, já ser casado. Como não existia, na época, o instituto do divórcio, esse indivíduo optava por viver uma união livre, à margem da sociedade.

Quando essas uniões eram rompidas, surgiram demandas no judiciário com o propósito de buscar uma solução para a divisão do patrimônio que foi adquirido em comum no decorrer daquele relacionamento. As primeiras soluções foram vistas dentro da legislação previdenciária ${ }^{19}$. Além disso, a mulher que não possuía nenhuma fonte de renda poderia receber alimentos de forma "camuflada", o que era denominado de "indenização por serviços domésticos", buscando compensar os serviços de cama e mesa por ela prestados. $O$ fundamento que se deu à época para isso foi a vedação do enriquecimento ilícito, pois o homem que se aproveita do trabalho e da dedicação de uma mulher não pode abandoná-la sem indenização ${ }^{20}$.

Em uma evolução jurisprudencial da época, passou-se a aceitar que a convivência daqueles que integram uma relação de concubinato era similar a uma sociedade de fato, tendo os conviventes assumido o status de sócios, com direito a uma parcela do patrimônio em comum, de acordo com o que cada um contribuiu. Esse entendimento restou sumulado pelo STF na sessão plenária de 03 de abril de $1964^{21}$.

Com o surgimento da Constituição Federal de 1988, o concubinato agora denominado união estável - recebeu a devida proteção jurídica do Direito de Família. $O$ art. 226, $\S 3^{\circ}$ do livro constitucional traz o termo "entidade

\footnotetext{
19 "Previdência social. Comprovação de estabilidade no concubinato e na dependência econômica da concubina com ex-segurado. Possibilidade de inscrição daquela como dependente, no órgão previdenciário". RT, 805/374.

20 DIAS, Maria Berenice. Manual de Direito de Família. São Paulo: Editora Revista dos Tribunais, 2016.

${ }^{21}$ Comprovada a existência de sociedade de fato entre os concubinos, é cabível a sua dissolução judicial, com a partilha do patrimônio adquirido pelo esforço em comum.
} 
familiar"22. Pablo Stolze Gagliano e Rodolfo Pamplona Filho não concordam com essa terminologia, sustentando que bastava dizer que a união estável seria reconhecida como forma de família, concluindo que a palavra "entidade" foi acrescida de forma desnecessária ${ }^{23}$. Tratando sobre a nova proteção constitucional que foi dada à união estável no livro constitucional, Maria Berenice Dias sustenta que pouco serviu, devido ao fato de, para os tribunais, a união estável permanecer no âmbito do direito das obrigações, a súmula 380 continuar sendo invocada, e a falta de avanço no direito sucessório ${ }^{24}$. Mesmo assim, ainda ocorreram alguns avanços, e a menção deles no presente artigo é válida.

De início, pode-se mencionar a equiparação da união estável com as outras modalidades de família. O fato de primeiro ser mencionado o casamento, depois, a união estável e, por último, a família monoparental, não significa que existam uma hierarquia entre esses dois modelos. As três espécies citadas acima merecem a mesma proteção dentro do ordenamento jurídico brasileiro.

Antes da chegada do Código Civil de 2002, duas importantes leis infraconstitucionais foram utilizadas para regular o tema: lei $8.971 / 94$ e a lei 9.278/96 - Lei da União Estável -. A primeira assegurou o direito dos companheiros a alimentos e à sucessão, todavia, na opinião de Maria Berenice Dias $^{25}$, esta carrega um "ranço preconceituoso", por excluir de seu texto normativo os separados de fato ${ }^{26}$. A união estável reconhecida por essa legislação era aquela que tivesse durado mais de cinco anos ou as quais houvessem nascido prole. Foi incluso, também, o companheiro(a) como herdeiro(a) legítimo(a), no caso da inexistência de ascendentes e descendentes.

22 Art. 226. A família, base da sociedade, tem especial proteção do Estado. (...) §3‥ Para efeito da proteção do Estado, é reconhecida a união estável entre o homem e a mulher como entidade familiar, devendo a lei facilitar sua conversão em casamento.

${ }^{23}$ GAGLIANO, Pablo Stolze; PAMPLONA FILHO, Rodolfo. Novo curso de direito civil - volume 6: Direito de família - As famílias em perspectiva constitucional. São Paulo: Saraiva, 2012. 24 DIAS, Maria Berenice. Manual de Direito de Família. São Paulo: Editora Revista dos Tribunais, 2016.

25 Ibidem.

${ }^{26}$ Art. $1^{\circ} \mathrm{A}$ companheira comprovada de um homem solteiro, separado judicialmente, divorciado ou viúvo, que com ele viva há mais de cinco anos, ou dele tenha prole, poderá valer-se do disposto na Lei no 5.478, de 25 de julho de 1968, enquanto não constituir nova união e desde que prove a necessidade. 
A lei da União Estável, de outra forma, não estabeleceu prazo para a relação ser considerada de união estável, incluiu os separados de fato, fixou a competência das varas de família para o julgamento dos litígios e reconheceu o direito real de habitação.

Com o surgimento do Código Civil de 2002, as leis 8.971/94 e 9.278/96 foram revogadas. Em cinco artigos (art. 1.723 a 1.727$)^{27}$ foram incorporados os princípios básicos dessa lei, assim como seus aspectos patrimoniais e pessoais. Outros dispositivos do Código fazem relação à união estável, como, por exemplo, o art. 1.694, que busca assegurar alimentos ao companheiro(a).

Por todos esses aspectos, podemos perceber que a união estável, após muitas discussões e alterações legislativas, conseguiu distanciar-se do caráter preconceituoso que carregava anteriormente, com a forma de concubinato, para ser vista como uma outra opção a figura do casamento, com menos formalidades do que o instituto anterior, mas, ainda assim, válida e respeitada.

\subsection{CONTRATO DE CONVIVÊNCIA}

De acordo com Francisco José Cahali ${ }^{28}$, o contrato de convivência é o instrumento pelo qual os sujeitos de uma união estável promovem

\footnotetext{
${ }^{27}$ Art. 1.723. É reconhecida como entidade familiar a união estável entre o homem e a mulher, configurada na convivência pública, contínua e duradoura e estabelecida com o objetivo de constituição de família. § $10 \mathrm{~A}$ união estável não se constituirá se ocorrerem os impedimentos do art. 1.521; não se aplicando a incidência do inciso VI no caso de a pessoa casada se achar separada de fato ou judicialmente. § 20 As causas suspensivas do art. 1.523 não impedirão a caracterização da união estável. Art. 1.724. As relações pessoais entre os companheiros obedecerão aos deveres de lealdade, respeito e assistência, e de guarda, sustento e educação dos filhos. Art. 1.725. Na união estável, salvo contrato escrito entre os companheiros, aplica-se às relações patrimoniais, no que couber, o regime da comunhão parcial de bens. Art. 1.726. A união estável poderá converter-se em casamento, mediante pedido dos companheiros ao juiz e assento no Registro Civil. Art. 1.727. As relações não eventuais entre o homem e a mulher, impedidos de casar, constituem concubinato.

28 CAHALI, José Francisco. Contrato de convivência na união estável. Saraiva: São Paulo, 2002 APUD GONÇALVES, Carlos Roberto. Direito civil brasileiro, volume 6: direito de família. Saraiva: São Paulo, 2017.
} 
regulamentações quanto aos reflexos da relação por eles constituída. Ainda de acordo com o mencionado autor ${ }^{29}$, o contrato:

(...) não reclama forma preestabelecida ou já determinada para sua eficácia, embora se tenha como necessário seja escrito, e não apenas verbal. Assim, poderá revestir-se da roupagem de uma convenção solene, escritura de declaração, instrumento contratual particular levado ou não a registro em Cartório de Títulos e Documentos, documento informal, pacto e, até mesmo, ser apresentado apenas como disposições ou estipulações esparsas, instrumentalizadas em conjunto ou separadamente, desde que contenham a manifestação bilateral da vontade dos companheiros.

Os conviventes podem, a qualquer tempo, regular as questões referentes à união estável, tanto pessoais como patrimoniais, deliberando, inclusive, efeitos retroativos. Outra característica desse contrato é que ele é feito de maneira informal, podendo ser de escrito particular ou escritura pública. Além disso, pode ou não ser levado a inscrição, registro ou averbação. José Francisco Cahali ${ }^{30}$ adverte que o contrato de convivência não tem força para criar a união estável, tendo sua eficácia condicionada à caracterização da entidade familiar em razão do comportamento das partes, mas, segundo Maria Berenice Dias ${ }^{31}$, é um forte indício de sua existência, visto que a união estável é formada com o atendimento dos seus requisitos legais.

Pablo Stolze Gagliano e Rodolfo Pamplona Filho ${ }^{32}$ elencam os atributos que compõem uma união estável. O primeiro elemento compositor de tal instituto é a publicidade, em detrimento do segredo, o que diferencia a união estável de uma relação clandestina. A ideia posta aqui é que o casal possa ser reconhecido socialmente como uma família.

\footnotetext{
29 Ibidem.

30 lbidem.

31 DIAS, Maria Berenice. Manual de Direito de Família. São Paulo: Editora Revista dos Tribunais, 2016.

32 GAGLIANO, Pablo Stolze; PAMPLONA FILHO, Rodolfo. Novo curso de direito civil - volume 6: Direito de família - As famílias em perspectiva constitucional. São Paulo: Saraiva, 2012.
} 
O segundo elemento é a continuidade, no sentido de animus de permanência, o que diferencia a união estável de um namoro. O terceiro elemento é a estabilidade, no sentido de uma convivência duradoura com a outra parte da relação. O quarto e último elemento é o objetivo da constituição da família, o que iria diferenciar a união estável de uma relação meramente obrigacional.

O autor também alista os elementos caracterizadores acidentais de uma união estável, quais sejam o tempo, a existência de prole e a exigência de coabitação. Embora não sejam essenciais, facilitam a comprovação judicial da união. Por um lado, levanta-se o argumento no sentido da insegurança gerada pela ausência de um lapso temporal - que foi definido como 5 anos na Lei de Alimentos e Sucessões, e retirado na Lei da União Estável -. Por outro, é necessário reconhecer que pode ocorrer situações de injustiça, como, por exemplo, um casal que não teve a união estável reconhecida por desfazerem o vínculo dias antes de completarem o prazo mínimo.

Com relação à coabitação, ela já não é afigurada indispensável, o que pode ser visto na súmula 382 do Supremo Tribunal Federal ${ }^{33}$. Como, então, pode-se definir com segurança que a relação posta ali é de união estável, visto que a coabitação é dispensável e a existência de tempo mínimo dessa união foi retirada?

Os elementos caracterizadores acidentais buscam apenas auxiliar 0 julgador do caso concreto a ver que aquele relacionamento é, realmente, de união estável. Não devem ser vistos como regramentos a serem seguidos nas relações. É necessário analisar a relação jurídica ali submetida a exame e ver o que pode ser aplicado ou não a ela.

O contrato de convivência é recomendado para que se possa dar certeza quanto ao tempo de vigência dessa união e para que possam ser

$33 \mathrm{~A}$ vida em comum sob o mesmo teto, more uxorio, não é indispensável à caracterização do concubinato. 
n. 1 (maio.2020)

definidos os efeitos patrimoniais, consoante Marcos Alves da Silva ${ }^{34}$, advogado e membro do Instituto Brasileiro de Direito de Família (IBDFAM). A união estável independe de qualquer solenidade, bastando o fato da vida em comum. Ele afirma, também, que o Brasil é um país com uma forte cultura cartorial, tendo o casamento como critério e regra para medir uma conjugalidade sem matrimônio.

Sendo assim, o que se busca com a utilização de tal contrato é uma proteção ao patrimônio dos envolvidos na relação. A união de fato terá início a partir do instante em que seus integrantes iniciarem a convivência, como se fossem casados, renovando dia a dia tal conduta, como assinala Antonio Carlos Mathias Coltro ${ }^{35}$, unindo-se a isso uma sucessão de fatos e eventos, permanência do relacionamento, continuidade do envolvimento, convivência more uxorio, a notoriedade, enfim, a soma de fatores objetivos e subjetivos que, do ponto de vista jurídico, definem a situação, conforme Zeno Veloso ${ }^{36}$.

Levando-se em consideração esses aspectos, o contrato de convivência não possui o condão de, unicamente, caracterizar uma união estável, mas sim prescrever a forma com que esta relação irá moldar os aspectos patrimoniais que poderão vir a ocorrer futuramente.

\section{POLIAMOR, POLIGAMIA E FAMÍLIAS PARALELAS}

O poliamor pode ser conceituado como a possibilidade de que três ou mais pessoas possuam a liberdade de ter mais de um relacionamento ao mesmo tempo. Estabelece uma ruptura com o princípio da monogamia, não sendo mais o casamento considerado uma condição natural e eterna, durando até quando

\footnotetext{
34 IBDFAM. União poliafetiva: escritura é necessária? Disponível em: < http://www.ibdfam.org.br/noticias/5970/Not\%25C3\%25A1rio\%252Bn\%25C3\%25A30\%252Bpod e\%252Bdeixar\%252Bd>. Acesso em 19 nov. 2018.

${ }^{35}$ COLTRO, Antonio Carlos Mathias. A união estável: um conceito?, in Direito de família aspectos constitucionais, civis e processuais, v. 2, p. 37 APUD GONÇALVES, Carlos Roberto. Direito civil brasileiro, volume 6: direito de família. Saraiva: São Paulo, 2017.

36 VELOSO, Zeno. Código Civil comentado, v. XVII, p. 117 APUD GONÇALVES, Carlos Roberto. Direito civil brasileiro, volume 6: direito de família. Saraiva: São Paulo, 2017.
} 
ambos parceiros acreditem estar satisfeitos, podendo essa relação ser rompida a qualquer momento, o que reflete a ênfase que vem sendo dada ao desenvolvimento da autonomia de cada cônjuge do que aos laços de dependência entre eles ${ }^{37}$.

É necessário ressaltar que a multiplicidade de parceiros não é a única característica que define uma união poliafetiva. Gabriel Dias da Silva ${ }^{38}$ elenca alguns critérios que podem ser extraídos de tais relações:

(...) são relacionamentos entre três ou mais pessoas, independendo o sexo ou preferência sexual dos mesmos, em um único núcleo, no qual todos os membros relacionam-se entre si, de maneira simultânea e conjunta. (...) ainda que seja entre mais de duas pessoas, implica em uma noção de unidade familiar, encontrando aí equivalência nas típicas relações monogâmicas.

Saliente-se que há diferença entre o poliamor e a poligamia. relacionamento monogâmico é entendido como aquele que ocorre entre duas pessoas que se relacionam entre si, formando um vínculo afetivo. A poligamia, em sua forma básica, de acordo com Gabriel Dias da Silva ${ }^{39}$, é o relacionamento entre mais de duas pessoas, onde um indivíduo se relaciona com mais de uma pessoa simultaneamente.

Por sua vez, Júlia Abagge de Macedo França ${ }^{40}$ reitera que a poligamia traz, em seu termo, uma carga pejorativa resultante de uma cultura patriarcal na qual, em regra, apenas um homem pode se casar com várias mulheres, não significando, necessariamente, que irá nutrir sentimento por todos os

${ }^{37}$ FREIRE, Sandra Elisa de Assis. Poliamor, uma forma não exclusiva de amar: correlatos valorativos e afetivos. 2013. $257 \mathrm{f}$. Tese (Doutorado em Psicologia Social) - João Pessoa: Centro de Ciências Humanas e Letras, Universidade Federal da Paraíba - UFPB, 2013.

${ }^{38}$ SILVA, Gabriel Dias da. Poliamor: uma análise acerca da constitucionalidade das uniões poliafetivas no Brasil. Santa Maria: Centro de Ciências Sociais e Humanas, Universidade Federal de Santa Maria - 2017.

39 SILVA, Gabriel Dias da. Poliamor: uma análise acerca da constitucionalidade das uniões poliafetivas no Brasil. Santa Maria: Centro de Ciências Sociais e Humanas, Universidade Federal de Santa Maria - 2017.

40 FRANÇA, Júlia Abagge de Macedo. Poligamia ou poliamor? A dignidade da pessoa humana pautada no afeto. Disponível em: < https://juliaabagge.jusbrasil.com.br/artigos/289614350/poligamia-ou-poliamor>. Acesso em 13 mar. 2019. 
participantes dessa relação. Existe uma hierarquia dentro das relações poligâmicas, centrada no elo que liga o principal membro do núcleo familiar com os outros integrantes que não possuem relação entre si.

Existem autores que relacionam, também, a poligamia com o conceito de famílias paralelas ou simultâneas. Sobre o assunto, Maria Berenice Dias ${ }^{41}$ trata da seguinte forma:

(...) Mesmo sendo casados ou tendo uma companheira, homens partem em busca de novas emoções sem abrir mão dos vínculos familiares que já possuem. Eles dispõem de habilidade para se desdobrar em dois relacionamentos simultâneos: dividem-se entre duas casas, mantêm duas mulheres e têm filhos com ambas. Quer se trate de um casamento e uma união estável, quer duas ou até mais uniões estáveis. É o que se chama de famílias simultâneas. Expressão preferível a famílias paralelas, porque linhas paralelas nunca se encontram, e a simultaneidade, muitas vezes, é conhecida e até aceita. Os filhos se conhecem e as mulheres sabem da existência da outra. No fim um arranjo que satisfaz a todos. A esposa tem um marido que ostenta socialmente. A companheira nada exige e se conforma em não compartilhar com o companheiro todos os momentos, mas o acolhe com afeto sempre que ele tem disponibilidade.

O que diferencia, então, o conceito de poliamor do que seria a poligamia ou famílias simultâneas? A existência de afetividade nas relações. Júlia Abagge de Macedo França $^{42}$ reforça que não é necessariamente 0 casamento a base dessa relação familiar, mas sim o afeto entre seus integrantes. A dinâmica do poliamor, de acordo com Sandra Elisa de Assis Freire ${ }^{43}$, está pautada no fato de que todas as pessoas envolvidas no relacionamento parecem

${ }^{41}$ DIAS, Maria Berenice. Manual de Direito de Família. São Paulo: Editora Revista dos Tribunais, 2016.

42 FRANÇA, Júlia Abagge de Macedo. Poligamia ou poliamor? A dignidade da pessoa humana pautada no afeto. Disponível em: < https://juliaabagge.jusbrasil.com.br/artigos/289614350/poligamia-ou-poliamor>. Acesso em 13 mar. 2019.

43 FREIRE, Sandra Elisa de Assis. Poliamor, uma forma não exclusiva de amar: correlatos valorativos e afetivos. 2013. 257 f. Tese (Doutorado em Psicologia Social) - João Pessoa: Centro de Ciências Humanas e Letras, Universidade Federal da Paraíba - UFPB, 2013. 
n. 1 (maio.2020)

se amar simultaneamente. Rafael da Silva Santiago ${ }^{44}$ alerta que chamar esse sentimento afetivo de amor é apenas uma questão terminológica, uma vez que a ideia do instituto é admitir uma pluralidade de sentimentos que se desenvolvem com relação a mais de uma pessoa, os quais vão além da mera relação sexual.

Outro autor, Paulo lotti ${ }^{45}$, ao dar o seu posicionamento sobre o tema, afirma que a diferença entre uniões poliafetivas e famílias paralelas está no fato de que se trata de uma situação fática onde uma pessoa forma mais de uma família conjugal por se relacionar com duas ou mais pessoas entre si. Maria Berenice Dias ${ }^{46}$ também defende que o melhor termo a ser utilizado seria "famílias simultâneas", porque, de acordo com a autora, fazendo uma analogia com a geometria, as linhas paralelas nunca se encontram, e a simultaneidade, no geral, é conhecida e pode até vir a ser aceita.

Pablo Stolze Gagliano e Rodolfo Pamplona Filho ${ }^{47}$, ao tratarem sobre o assunto em seu manual de direito civil, fazem uma relação entre as famílias paralelas, dever de fidelidade e relações de concubinato.

A pergunta feita por eles no capítulo referente ao tema é bastante pertinente - o Direito deve tutelar essas relações? -, tendo em vista que, no ordenamento jurídico brasileiro e na sociedade como um todo, existe um pensamento conservador no que diz respeito às famílias paralelas, buscando a preservação daquilo que é denominado "família tradicional brasileira": um casal, heterossexual, com filhos, sendo o homem o chefe da família e a mulher o seu suporte.

$\mathrm{Na}$ época atual, essa ideia não pode ser disseminada como a regra na formação das famílias. O que se vê é uma variedade na constituição dessas

44 SANTIAGO, Rafael da Silva. Poliamor e direito das famílias: reconhecimento e consequências jurídicas. Curitiba: Juruá, 2015 APUD FRANÇA, Júlia Abagge de Macedo. Poligamia ou poliamor? A dignidade da pessoa humana pautada no afeto. Disponível em: $<$ https://juliaabagge.jusbrasil.com.br/artigos/289614350/poligamia-ou-poliamor>. Acesso em 13 mar. 2019.

45 VECHIATTI, Paulo Roberto lotti. União poliafetiva como entidade familiar constitucionalmente protegida. Minas Gerais: Revista Libertas, 2016.

46 DIAS, Maria Berenice. Manual de Direito de Família. São Paulo: Editora Revista dos Tribunais, 2016.

47 GAGLIANO, Pablo Stolze. PAMPLONA FILHO, Rodolfo. Novo curso de direito civil - volume 6: Direito de família - As famílias em perspectiva constitucional. São Paulo: Saraiva, 2012. 
famílias, levando aos conceitos de "tipos de família", no qual se adentra a ideia das famílias paralelas e poliafetivas.

O princípio da monogamia, explanado anteriormente, juntamente com o conservadorismo e as noções que o permeiam, é o que torna difícil o avanço do tema nas discussões dentro dos conselhos que o regulam.

\subsection{DEVER DE FIDELIDADE X DEVER DE LEALDADE}

O dever de fidelidade, pautado como um dos princípios do casamento ou união estável, pode ser visto no artigo $1.566^{48}$, abordando a "fidelidade recíproca", e no artigo 1.72449 , quando menciona o "dever de lealdade". Os termos são definidos no dicionário Michaelis de Língua Portuguesa ${ }^{50}$ da seguinte forma:

Fidelidade: 1 Característica ou qualidade do que é fiel, do que respeita alguém ou algo; lealdade (...). 2 Constância nas afeições e nos compromissos assumidos com pessoas ou instituições (...). 3 Compromisso de não cometer traição ao parceiro numa relação amorosa (...).

Lealdade: 1 Conformidade com os preceitos que regem a honra, o dever e a probidade; dignidade, honradez, integridade (...). 2 Cumprimento da palavra dada; fidelidade, respeito, responsabilidade (...).

No que diz respeito ao assunto, Maria Berenice Dias ${ }^{51}$ diz o seguinte:

\footnotetext{
48 Art. 1.566. São deveres de ambos os cônjuges: I - fidelidade recíproca; II - vida em comum, no domicílio conjugal; III - mútua assistência; IV - sustento, guarda e educação dos filhos; V respeito e consideração mútuos.

49 Art. 1.724. As relações pessoais entre os companheiros obedecerão aos deveres de lealdade, respeito e assistência, e de guarda, sustento e educação dos filhos.

50 Michaelis. Moderno dicionário da Língua Portuguesa. São Paulo: Editora Melhoramentos, 2019.

51 DIAS, Maria Berenice. Os princípios da lealdade e da confiança na família. Disponível em: $<$

http://www.mariaberenice.com.br/manager/arq/(cod2_564)18_os_principios_da_lealdade_e_d a_confianca_na_familia.pdf>. Acesso em 20 mai $201 \overline{1}$.
} 
Os deveres de fidelidade e de lealdade cristalizam tanto o princípio da boa-fé objetiva, como o da proibição de comportamento contraditório, que compõem a tutela da confiança. Nada mais do que a consagração do princípio nemo potest venire contra factum proprio, ou seja, a imposição da uma atuação refletida, um agir pensando no outro, uma postura de lealdade, sem abuso. Este conceito, ainda que construído no campo obrigacional, não é diferente das expectativas que permeiam os vínculos afetivos.

Pensando pelo viés colocado por Maria Berenice Dias na citação acima, se a fidelidade está relacionada com a tutela da confiança e do agir pensando no outro, podemos associá-la com seu oposto, a infidelidade, que seria caracterizada pela perda de confiança e a violação da expectativa de construção de uma vida em comum.

Essa quebra de expectativa estaria atrelada a preservação do princípio da monogamia, todavia, não se pode relacionar o dever de fidelidade casamento - ou lealdade - união estável - com as relações poliafetivas e paralelas, haja vista que ele vem sendo mitigado a partir do mútuo conhecimento e aceitação dos outros membros dessa relação ${ }^{52}$, que seria requisito para a formação desses modelos familiares.

Outrossim, deve-se ressaltar que o dever de fidelidade está pautado nas exigências para o casamento, e o dever de lealdade está voltado para a união estável. Fidelidade e lealdade teriam o mesmo significado? O conceito de lealdade é mais amplo do que o de fidelidade de acordo com a definição apresentada pelo dicionário, todavia, consoante Júlio César Ballerini Silva ${ }^{53}$, a norma não disciplina o que seria, exatamente, a fidelidade e lealdade dentro do contexto da Codificação. O mesmo autor ${ }^{54}$, ao tratar sobre relacionamentos

\footnotetext{
52 GAGLIANO, Pablo Stolze. Novo curso de direito civil - volume 6: Direito de família - As famílias em perspectiva constitucional. São Paulo: Saraiva, 2012.

${ }^{3}$ SILVA, Júlio César Ballerini. Dever de fidelidade ou dever de lealdade no bojo das relações familiares? Disponível em: <https://www.migalhas.com.br/dePeso/16,Ml256662,41046Dever+de+fidelidade+ou+dever+de+lealdade+no+bojo+das+relacoes $>$. Acesso em 22 mai 2019.

54 Ibidem.
} 
abertos, faz a seguinte afirmação, que pode ser relacionada com os conceitos de poliafetividade e famílias paralelas:

Deve-se buscar algo mais amplo que seria a lealdade. Ou seja, pessoas capazes tem liberdade de consentir ou não, em relação às práticas do uns dos outros. Se ambos mantém um relacionamento aberto (prática corrente na atualidade - 0 assim chamado casamento ou relação eudemônico), ou seja, se ambos concordam e se permitem tal situação, todos sabendo o que se passa, pelo óbvio, por uma questão de boa-fé, não haverá dano moral, não haverá qualquer violação passível de indenização.

Há lealdade, sem fidelidade, na acepção estrita do termo. $E$ salvo o entendimento dos mais conservadores, não haveria qualquer óbice técnico (não obstante exista a família tradicional matrimonial com o dever de fidelidade - o fato é que, se houver violação a esse dever, o máximo que se admitiria em discussão em sede de culpa muitos autores de peso sequer admitem isso - seria a indenização - mas se há prova de tal regra clara não há margem para indenização - se todos sabem e permitem e se ambos concordam com isso não pode haver margem para a indenização - não haveria ultraje ou sensação de ilusão ou eventuais problemas psicológicos).

Outros autores, como Lara Marcelino de Souza e Lorena Nogueira Rêgo ${ }^{55}$, ao fazerem relação com a teoria de Engels, aduzem que o princípio da monogamia tem mais cunho patrimonial do que amoroso, buscando a segurança jurídica dos bens e, também, a proteção do princípio da boa-fé na relação conjugal, reforçando as expectativas da existência da monogamia dentro do convívio entre os parceiros.

Fidelidade e lealdade, na discussão sobre requisitos do casamento e união estável, não podem ser vistas dentro de um mesmo patamar. Se todas as partes envolvidas tem conhecimento das outras relações que ocorrem de maneira paralela ou simultânea, não há como vir a ter a quebra do dever de

55 SOUZA, Lara Marcelino de; RÊGO, Lorena Nogueira. (2013). "Contornos jurídicos, filosóficos e sociais da monogamia: paradigmas do poliamor no Direito de Família". Revista FIDES, n. 2, v.4: p. 184-202, jul./dez APUD GAMBOGI, Luís C. B.; POGGIALI, Lívia H. O. União poliafetiva: família de fato. E de direito? Paraíba: UFPB - Revista Ártemis, 2018. 
lealdade, na situação da união estável poliafetiva, por ser algo que já foi acordado desde o início daquela relação.

\subsection{INTERVENÇÃO DO ESTADO NAS RELAÇÕES PESSOAIS}

É notória a necessidade de tutela de determinadas situações pelo Código Civil, porém, o questionamento que fica é: até que ponto pode o Estado intervir nas relações derivadas de um determinado relacionamento? Essa intromissão é vista também no Código Penal, no artigo $235^{56}$, quando tipifica o crime de bigamia. A inserção desse tipo penal pode ser analisada juntamente com o comportamento que se espera das pessoas ao viver em sociedade.

Moralmente falando, não é "certo", "moral" ou "aceitável" alguém se casar com mais de uma pessoa ao mesmo tempo. Como o Direito, de certa forma, tem grande relação com a moral, a Codificação - tanto civil quanto penal - irá legislar e tipificar situações que, seguindo os princípios basilares e antigos sobre a formação e conceito de família, se tornaram padrão até os dias atuais. A amplitude do princípio da monogamia pode ser vista de tal forma que ultrapassou o Código Civil e adentrou no Código Penal nas seções de crime contra a família, buscando a proteção de conceitos que não se adaptaram ao contemporâneo.

Se a noção de família está inserida dentro de um contexto íntimo e pessoal, não tem motivo para a regulação do Estado sobre o assunto. Consoante Renata Vilela Multedo ${ }^{57}$, quando existe essa ocorrência, há uma inversão dos valores constitucionais, porque não pode ser sustentado que os indivíduos se adequem a um modelo definido previamente pelo Estado e atenda aos interesses dele e deixem de lado as próprias vontades.

\footnotetext{
${ }^{56}$ Art. 235. Contrair alguém, sendo casado, novo casamento: Pena - reclusão, de dois a seis anos.

${ }^{57}$ MULTEDO, Renata Vilela. Liberdade e família - limites para a intervenção do Estado nas relações conjugais e parentais. Rio de Janeiro: Processo, 2017 APUD GAMBOGI, Luís C. B.; POGGIALI, Lívia H. O. União poliafetiva: família de fato. E de direito? Paraíba: UFPB - Revista Ártemis, 2018.
} 
n. 1 (maio.2020)

Também dependerá do ponto de vista de cada pessoa sobre esse determinado assunto: alguém pode afirmar que há uma quebra do princípio da boa-fé e da dignidade da pessoa humana na contração de mais de um casamento ou união estável ao mesmo tempo, estando somente uma das partes envolvidas, e na formação de famílias poliafetivas; enquanto outro pode aduzir que os princípios fundamentais da pessoa humana estão sendo devidamente respeitados na formação dessas relações.

Concordando com o posicionamento de Luís Gambogi e Lívia Poggiali ${ }^{58}$, se as pessoas envolvidas acordam, de maneira consensual, que a forma não monogâmica de família está adequada para o relacionamento que possuem, não cabe ao Estado negar a tutela dessa situação.

Dessa forma, o Estado deverá se envolver em situações pessoais dos relacionamentos quando assim the for requisitado pelos seus componentes, caso contrário, estará visando defender uma moral que está sendo transformada diariamente junto com seus indivíduos e que não se adequa as situações que ocorrem nos dias atuais.

\section{ESCRITURA PÚBLICA DE REGISTRO DAS UNIÕES POLIAFETIVAS}

A primeira escritura pública de registro de união poliafetiva ocorreu em 2012, no cartório de Tupã, cidade de São Paulo, realizada pela tabeliã de notas e protestos Cláudia do Nascimento Domingues. A tabeliã afirmou que os envolvidos na relação, duas mulheres e um homem, já viviam em união estável e visavam garantir publicamente os seus direitos, o que os levou a buscar a garantia de seus direitos.

$\mathrm{Na}$ escritura, restou estabelecido um regime patrimonial de comunhão parcial, análogo ao regime da comunhão parcial de bens disposto no Código Civil nos artigos 1.658 a 1.666, onde decidiram que um dos conviventes irá exercer a

${ }^{58}$ GAMBOGI, Luís C. B.; POGGIALI, Lívia H. O. União poliafetiva: família de fato. E de direito? Paraíba: UFPB - Revista Ártemis, 2018. 
administração dos bens, estando também contido, em tal documento, os direitos e deveres que devem possuir dentro da relação, tais como assistência material e emocional eventualmente para o bem estar comum, o dever de lealdade e manutenção da harmonia da convivência entre os três ${ }^{59}$.

O tema voltou a ser discussão novamente em 2016, quando, no $15^{\circ}$ Ofício de Notas da Barra da Tijuca, no Rio de Janeiro, a tabeliã Fernanda de Freitas Leitão realizou a primeira união estável poliafetiva entre um homem e duas mulheres no estado. Todavia, ela já havia realizado uma união entre três mulheres, em outubro de 2015.

A repercussão sobre o tema foi enorme, de tal forma que a Corregedoria Geral da Justiça do Estado do Rio de Janeiro lançou nota técnica sobre o tema, na qual afirmou o seguinte ${ }^{60}$ :

(...) A escritura declaratória é lavrada pelo tabelião de notas a pedido da parte, que declara um fato ou direito, e no caso em questão, foi sobre um fato préexistente: o convívio de três pessoas. A citada escritura não tem o condão de criar direitos, uma vez que a união poliafetiva não é reconhecida no ordenamento jurídico. Assim como alerta na própria escritura lavrada pela delegatária do Cartório do $15^{\circ}$ Ofício de Notas da Comarca da Capital: "os direitos concernentes à união poliafetiva são incipientes, não ostentando, até o presente momento, legislação e jurisprudência sólidas. Por esta razão, os efeitos desta escritura poderão ser mitigados por decisão judicial ou mesmo recusados".

Deve ser esclarecido ainda que a realização de um casamento somente pode ser feita perante os cartórios com atribuição de Registro Civil de Pessoas Naturais (RCPN), e as escrituras declaratórias de

59 IBDFAM. Escritura reconhece união afetiva a três. Disponível em: http://www.ibdfam.org.br/noticias/4862/novosite. Acesso em 01 mai 2020.

60 CORREGEDORIA GERAL DA JUSTIÇA DO ESTADO DO RIO DE JANEIRO. Assessoria de Imprensa. NOTA CGJ: Esclarecimento sobre escritura declaratória de união poliafetiva. 2016. Notícia publicada pela Assessoria de Imprensa da CGJ. Disponível em: http://cgj.tjrj.jus.br/pagina-

inicial?p_p_id=com_liferay_portal_search_web_portlet_SearchPortlet\&p_p_lifecycle=0\&p_p_st ate $=$ maximized\&p_p_mode $=v i e w \bar{\varepsilon} \_c o m \_$liferay_portal_search_web_portlet_SearchPortlet_mvc

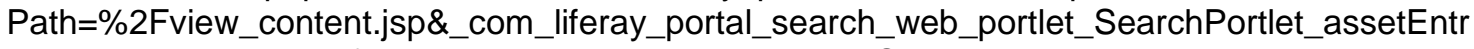
yld=5209276\&_com_liferay_portal_search_web_portlet_SearchPortlet_type =content\&inheritRe direct=true. Acesso em 01 mai 2020. 
união estável (entre duas pessoas) nos cartórios de Ofício de Notas. Dessa maneira, os efeitos de uma escritura declaratória de união poliafetiva não são equiparados aos efeitos do registro de casamento ou da escritura de união estável.

A Corregedoria Geral da Justiça comunica também que, embora tenha sido lavrada tal escritura pelo Cartório do $15^{\circ}$ Ofício de Notas da Comarca da Capital, os demais cartórios com atribuição notarial no estado não estão obrigados à confecção de escrituras semelhantes, uma vez que a união poliafetiva não é respaldada por lei.

Marcos Alves da Silva ${ }^{61}$, em reportagem sobre o tema, afirma que o Brasil é um país cartorial, tendo o casamento como regra para que possa medir uma conjugalidade sem matrimônio. Ele também sustenta que não existe escritura pública que constitua união estável, tendo em vista que os seus prérequisitos exigidos por lei, como a publicidade, durabilidade, continuidade e a intenção de constituir família são o que, verdadeiramente, constituem uma união estável.

A declaração teria apenas duas vantagens, de acordo com o mesmo autor $^{62}$ : dar certeza quanto ao tempo de vigência da união estável e definição, pelos companheiros, dos efeitos patrimoniais de tal ato.

Neste diapasão, devemos lembrar que o direito de família está sempre em transformação, adequando-se as realidades consoante a forma na qual a sociedade vem sofrendo transições. Antes, somente o casamento era visto como forma de constituir família, abrindo espaço para a validação da união estável, e, dentro destes dois institutos, as uniões homoafetivas também tiveram que lutar em busca de seu espaço, reforçando a ideia de que as leis devem acompanhar as mudanças que ocorrem no mundo.

61 IBDFAM. União poliafetiva: escritura é necessária? Disponível em: < http://www.ibdfam.org.br/noticias/5970/Not\%25C3\%25A1rio\%252Bn\%25C3\%25A30\%252Bpod e\%252Bdeixar\%252Bd>. Acesso em 19 nov. 2018.

62 Ibidem. 


\subsection{POSIÇÕES FAVORÁVEIS}

Uma das maiores defensoras da possibilidade da utilização da escritura pública de registro de uniões poliafetivas é Maria Berenice Dias, que já foi citada largamente ao longo deste artigo. Em breve texto escrito sobre o tema, ela afirma que, sob o ponto de vista do direito familista, sucessório e contratual ${ }^{63}$ :

(...) Negar a existência de famílias poliafetivas como entidade familiar é simplesmente impor a exclusão de todos os direitos no âmbito do direito das famílias e sucessório. Pelo jeito, nenhum de seus integrantes poderia receber alimentos, herdar, ter participação sobre os bens adquiridos em comum. Sequer seria possível invocar 0 direito societário com 0 reconhecimento de uma sociedade de fato, partilhando-se os bens adquiridos na sua constância, mediante a prova da participação efetiva na constituição do acervo patrimonial.

Marcos Alves da Silva fez tese de doutorado na Universidade do Estado do Rio de Janeiro sobre o tema. Intitulada "Da superação da monogamia como princípio estruturante do estatuto jurídico da família", o autor defende que ${ }^{64}$ o princípio jurídico da monogamia legitima a dominação masculina, além de apontar o fato de que as "concubinas" são excluídas da condição de sujeito de direito, permanecendo a margem da sociedade.

\subsection{POSIÇÕES CONTRÁRIAS}

Regina Beatriz Tavares da Silva é abertamente contra a utilização da escritura pública de união estável para registro de uniões poliafetivas. A autora já declarou ${ }^{65}$, em entrevista, que o artigo 226, $3^{\circ}$, define união estável como

63 DIAS, Maria Berenice. Escritura de união poliafetiva: possibilidade. Disponível em: https://arpen-sp.jusbrasil.com.br/noticias/100173615/artigo-escritura-de-uniao-poliafetivapossibilidade-por-maria-berenice-dias. Acesso em 01 mai 2020.

64 SILVA, Marcos Alves da. Da superação da monogamia como princípio estruturante do estatuto jurídico da família. 2012. $295 \mathrm{f}$. Tese (Doutorado em Direito). Rio de Janeiro: Faculdade de Direito, Universidade do Estado do Rio de Janeiro, 2012.

65 MANSUR, PEDRO.'Poliafetivos não tem direito de família', diz advogada contrária às uniões. Jornal $O$ Globo, Rio de Janeiro, 25/06/2016. Disponível em: 
sendo a união entre duas pessoas, o que tornaria a escritura inconstitucional e, por consequência, o registro feito pelos cartórios de Tupã e da Barra da Tijuca violadores da Constituição Federal.

Além disso, na mesma entrevista, afirma o seguinte ${ }^{66}$ :

(...) Esse tipo de união, poliafetiva, não tem direitos de família e a sucessões. Elas dizem que os três, esses chamados trisal, têm dever e direitos de lealdade, fidelidade, assistência, presunção de partilha de patrimônio entre os membros (...). No entanto, essas pessoas não têm esses direitos, é um engodo, estão fazendo pessoas incidirem em erro, saem de lá achando que têm esse direito, quando não têm. Acham que a lei vale para elas, quando não vale.

Rolf Madaleno também é um dos autores que defende a impossibilidade da realização desse tipo de união. $\mathrm{O}$ autor alega que o princípio da monogamia ainda é ordenador de uma conduta humana ao menos preferencial da organização das relações jurídicas da família do mundo ocidental, e que somente o Poder Judiciário está capacitado para reconhecer circunstanciais efeitos aos contratos de relações poliafetivas.

Ele também diz que não há dispositivo de lei que reconheça a validade de uma relação poliafetiva, e muito menos a exigir a escritura pública como condição de manifestação de vontade, publicidade, segurança e solenidade imposta para a constituição e validade de uma relação de poliamor.

\subsection{ENTENDIMENTO DO CONSELHO NACIONAL DE JUSTIÇA}

O Conselho Nacional de Justiça (CNJ), em plenário realizado no dia 26/06/2018, deliberou que os cartórios brasileiros não estão autorizados a registrar uniões poliafetivas, entre três ou mais pessoas, em escrituras públicas, seguindo o entendimento de que esse tipo de documento atesta um ato de fé

https://oglobo.globo.com/sociedade/poliafetivos-nao-tem-direito-de-familia-diz-advogadacontraria-as-unioes-19360291. Acesso em 01 mai 2020.

66 Ibidem. 
pública e implica o reconhecimento de direitos a casais ligados por casamento ou união estável, como, por exemplo, direito à herança ou previdenciários ${ }^{67}$.

O relator do processo foi o ministro João Otávio de Noronha, que afirmou que ${ }^{68}$ as competências do CNJ se limitam ao controle administrativo e não jurisdicional, além do fato de que a emissão desse tipo de documento não tem respaldo na legislação nem na jurisprudência do Supremo Tribunal Federal.

O ministro ainda diz que ${ }^{69}$ :

\begin{abstract}
"(Nesse julgamento) eu não discuto se é possível uma união poliafetiva ou não. $\mathrm{O}$ corregedor normatiza os atos dos cartórios. Os atos cartorários devem estar em consonância com o sistema jurídico, está dito na lei. As escrituras públicas servem para representar as manifestações de vontade consideradas lícitas. Um cartório não pode lavrar em escritura um ato ilícito como um assassinato, por exemplo".
\end{abstract}

Carmen Lúcia reitera que ${ }^{70}$ a liberdade de conviver não está sob a competência do $\mathrm{CNJ}$, haja vista que todos são livres de acordo com a Constituição. A atribuição do CNJ é de tão somente tratar do dever e do poder dos cartórios de lavrar as escrituras.

\title{
CONCLUSÃO
}

Neste diapasão, podemos concluir que, da mesma forma que a aceitação da união estável como forma de constituição válida de família e da permissão de realização de casamentos e uniões estáveis homoafetivas

67 CONSELHO NACIONAL DE JUSTIÇA. Cartórios são proibidos de fazer escrituras públicas de relações poliafetivas. Disponível em: https://www.cnj.jus.br/cartorios-saoproibidos-de-fazer-escrituras-publicas-de-relacoes-poliafetivas/. Acesso em 02 mai 2020.

68 Ibidem.

69 Ibidem.

70 CONSELHO NACIONAL DE JUSTIÇA. Cartórios são proibidos de fazer escrituras

públicas de relações poliafetivas. Disponível em: https://www.cnj.jus.br/cartorios-saoproibidos-de-fazer-escrituras-publicas-de-relacoes-poliafetivas/. Acesso em 02 mai 2020. 
n. 1 (maio.2020)

passaram por diversas dificuldades e impedimentos para que pudessem ser reconhecidas, o registro das uniões poliafetivas irá percorrer caminho similar.

O direito familista caminha lado a lado com a sociedade, acompanhando as mudanças que ocorreram ao longo do tempo e tentando se desprender de princípios, como o da monogamia, que ainda é bastante defendido por diversos doutrinadores e impede o avanço de discussões como a utilização da escritura pública de registro de uniões poliafetivas, que, cada vez mais, vem se mostrando parte dos debates atuais.

A realidade é que essa forma de relacionamento não parará de existir. Aqueles que são integrantes desse tipo de união buscam, apenas, o reconhecimento jurídico desse fato para que possam proteger o seu patrimônio e o de seus companheiros - assim como fazem aqueles que possuem um relacionamento convencional e vão em busca de oficialização de um casamento ou união estável.

O que deve ser feito pelo Estado é dar o mesmo tratamento as relações de poliafetividade que é dado as relações monogâmicas, percebendo que não há necessidade de intervenções visando a proibição e adequando o direito às temáticas atuais do debate.

\section{REFERÊNCIAS}

ANDRADE, Marcelo Caetano Bittencourt Pizzani Ribeiro de. Respirar o amor aspirando liberdade: o poliamor no ordenamento jurídico brasileiro. Salvador: Faculdade de Direito da UFBA, Universidade Federal da Bahia - UFBA, 2018.

BRASIL. Constituição (1988). Constituição da República Federativa do Brasil de 1988 Disponível em: $<$ http://www.planalto.gov.br/ccivil_03/constituicao/constituicao.htm>. Acesso em 8 jan. 2019.

Decreto-Lei 2.848, de 07 de dezembro de 1940. Institui o Código Penal. Disponível em: < >. Acesso em: 22 mai 2019. 
Disponível

Lei $\mathrm{n}^{\circ}$ 10.406, de 10 de janeiro de 2002. Institui o Código Civil. <http://www.planalto.gov.br/ccivil_03/Leis/2002/L10406.htm>. Acesso em: 8 jan. 2019.

. Superior Tribunal Federal. Súmula no $\mathbf{3 8 0}$. Comprovada a existência de sociedade de fato entre os concubinos, é cabível a sua dissolução judicial, com a partilha do patrimônio adquirido pelo esforço em comum. Disponível em: < http://www.stf.jus.br/portal/jurisprudencia/menusumariosumulas. asp?sumula=24 82>. Acesso em 8 jan. 2019.

. Superior Tribunal Federal. Súmula no 382. A vida em comum sob o mesmo teto, more uxorio, não é indispensável à caracterização do concubinato. Disponível em: http://www.stf.jus.br/portal/jurisprudencia/menusumariosumulas.asp?sumula=24 88>. Acesso em 9 jan. 2019.

Carta Forense. Escritura de união poliafetiva: impossibilidade. Disponível

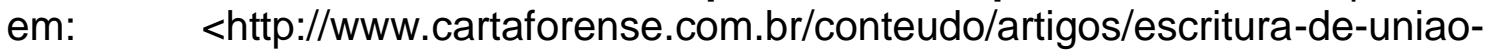
poliafetiva-impossibilidade/9754>. Acesso em 18 dez. 2018.

CONSELHO NACIONAL DE JUSTIÇA. Cartórios são proibidos de fazer escrituras públicas de relações poliafetivas. Disponível em: https://www.cnj.jus.br/cartorios-sao-proibidos-de-fazer-escrituras-publicas-derelacoes-poliafetivas/. Acesso em 02 mai 2020.

2013. Disponível em: < http://www.cnj.jus.br/busca-atosadm?documento=2504>. Acesso em 23 mai 2019.

CORREGEDORIA GERAL DA JUSTIÇA DO ESTADO DO RIO DE JANEIRO. Assessoria de Imprensa. NOTA CGJ: Esclarecimento sobre escritura declaratória de união poliafetiva. 2016. Notícia publicada pela Assessoria de Imprensa da CGJ. Disponível em: http://cgj.tjrj.jus.br/paginainicial?p_p_id=com_liferay_portal_search_web_portlet_SearchPortlet\&p_p_lifec $y c l e=0 \& p \_p \_s t a t e=m a x i m i z e d \& p \_p \_m o d e=v i e w \& \_c o m \_l i f e r a y \_p o r t a l \_s e a r c h \_$ web_portlet_SearchPortlet_mvcPath=\%2Fview_content.jsp\&_com_liferay_port al_search_web_portlet_SearchPortlet_assetEntryld $=5209276 \&$ \&com_liferay_po rtal_search_web_portlet_SearchPortlet_type $=$ content\&inheritRedirect=true. Acesso em 01 mai 2020.

DIAS, Maria Berenice. Manual de Direito de Família. São Paulo: Editora Revista dos Tribunais, 2016.

DIAS, Maria Berenice. Os princípios da lealdade e da confiança na família. Disponível em: 
n. 1 (maio.2020)

http://www.mariaberenice.com.br/manager/arq/(cod2_564)18_os_principios_d a_lealdade_e_da_confianca_na_familia.pdf $>$. Acesso em 20 mai 2019.

FRANÇA, Júlia Abagge de Macedo. Poligamia ou poliamor? A dignidade da pessoa humana pautada no afeto. Disponível em: < https://juliaabagge.jusbrasil.com.br/artigos/289614350/poligamia-ou-poliamor>. Acesso em 13 mar. 2019.

FREIRE, Sandra Elisa de Assis. Poliamor, uma forma não exclusiva de amar: correlatos valorativos e afetivos. 2013. $257 \mathrm{f}$. Tese (Doutorado em Psicologia Social) - João Pessoa: Centro de Ciências Humanas e Letras, Universidade Federal da Paraíba - UFPB, 2013

GAGLIANO, Pablo Stolze. PAMPLONA FILHO, Rodolfo. Novo curso de direito civil - volume 6: Direito de família - As famílias em perspectiva constitucional. São Paulo: Saraiva, 2012.

GAMBOGI, Luís C. B.; POGGIALI, Lívia H. O. União poliafetiva: família de fato. E de direito? Paraíba: UFPB - Revista Ártemis, 2018

GOMES, Orlando. Direito de Família. Rio de Janeiro: Forense, 2000.

GONÇALVES, Carlos Roberto. Direito civil brasileiro, volume 6: direito de família. Saraiva: São Paulo, 2017.

IBDFAM. Escritura reconhece união afetiva a três. Disponível em: http://www.ibdfam.org.br/noticias/4862/novosite. Acesso em 01 mai 2020.

Monogamia, desejo e famílias paralelas. Disponível em: < http://www.ibdfam.org.br/noticias/4989/Monogamia,+desejo+e+fam\%C3\%ADlia s+paralelas>. Acesso em 9 jan. 2019.

União poliafetiva: escritura é necessária? Disponível em: < http://www.ibdfam.org.br/noticias/5970/Not\%25C3\%25A1 rio\%252Bn\%25C3\%2 5A30\%252Bpode\%252Bdeixar\%252Bd>. Acesso em 19 nov. 2018.

em:

Uniões simultâneas, monogamia e dever a fidelidade. Disponível

<http://www.ibdfam.org.br/noticias/5153/Uni\%C3\%B5es+simult\%C3\%A2neas\% 2C+monogamia+e+dever+a+fidelidade>. Acesso em 18 dez. 2018.

IBGE - INSTITUTO BRASILEIRO DE GEOGRAFIA E ESTATÍSTICA. Nupcialidade e fecundidade. Disponível em: < https://cnae.ibge.gov.br/en/component/content/article/95-7a12/7a12-vamosconhecer-o-brasil/nosso-povo/1472-nupcialidade-efecundidade.html? ltemid=6160>. Acesso em 13 mar. 2019. 
MANSUR, PEDRO.'Poliafetivos não tem direito de família', diz advogada contrária às uniões. Jornal $O$ Globo, Rio de Janeiro, 25/06/2016. Disponível em: https://oglobo.globo.com/sociedade/poliafetivos-nao-tem-direito-de-familiadiz-advogada-contraria-as-unioes-19360291. Acesso em 01 mai 2020.

Michaelis. Moderno dicionário da Língua Portuguesa. São Paulo: Editora Melhoramentos, 2019.

MULTEDO, Renata Vilela. Liberdade e família - limites para a intervenção do Estado nas relações conjugais e parentais. Rio de Janeiro: Processo, 2017

PEREIRA, Rodrigo da Cunha. Direito de família: uma abordagem psicanalítica. Rio de Janeiro: Editora Forense, 2012.

RUZYK, Carlos Eduardo Pianovski. Famílias simultâneas: da unidade codificada à pluralidade constitucional. Rio de Janeiro: Renovar, 2005

SANTIAGO, Rafael da Silva. Poliamor e direito das famílias: reconhecimento e consequências jurídicas. Curitiba: Juruá, 2015

SANTOS, Frederico Fernandes dos. O que são princípios? Suas fases, distinções e juridicidade. Disponível em: <https://jus.com.br/artigos/45194/oque-sao-principios-suas-fases-distincoes-e-juridicidade>. Acesso em 9 jan.2019.

SILVA, Gabriel Dias da. Poliamor: uma análise acerca da constitucionalidade das uniões poliafetivas no Brasil. Santa Maria: Centro de Ciências Sociais e Humanas, Universidade Federal de Santa Maria - 2017.

SILVA, Júlio César Ballerini. Dever de fidelidade ou dever de lealdade no bojo das relações familiares? Disponível em: $<$ https://www.migalhas.com.br/dePeso/16,Ml256662,41046-

Dever+de+fidelidade+ou+dever+de+lealdade+no+bojo+das+relacoes $>$. Acesso em 22 mai 2019.

SILVA, Marcos Alves da. Da superação da monogamia como princípio estruturante do estatuto jurídico da família. 2012. 295 f. Tese (Doutorado em Direito). Rio de Janeiro: Faculdade de Direito, Universidade do Estado do Rio de Janeiro, 2012.

SILVA, Regina Beatriz Tavares da. As tentativas de destruição da Família Brasileira. Disponível em: <http://www.reginabeatriz.com.br/as-tentativas-dedestruicao-da-familia-brasileira>. Acesso em 18 dez. 2018.

TARTUCE, Flávio. Direito civil, v. 5: Direito de família. 12 ed. rev., atual e ampl. Rio de Janeiro: Forense, 2017. 
Revista Direito e Sexualidade

n. 1 (maio.2020)

VECHIATTI, Paulo Roberto lotti. União poliafetiva como entidade familiar constitucionalmente protegida. Minas Gerais: Revista Libertas, 2016. 